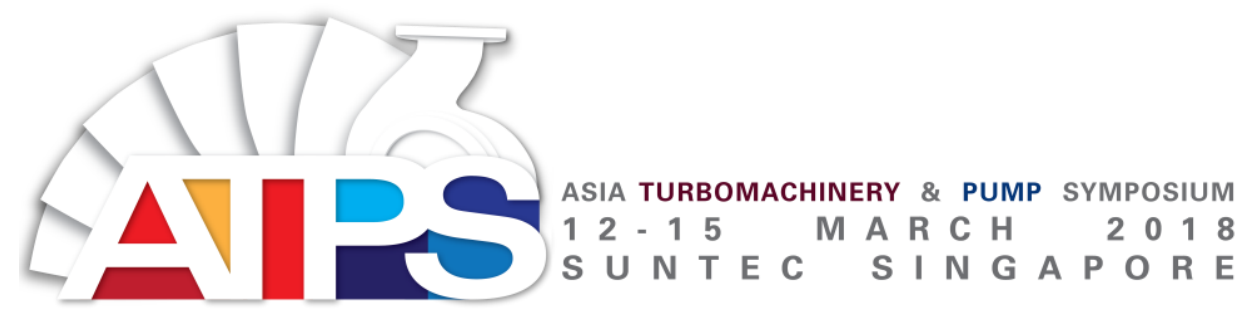

\title{
STATIC AND ROTORDYNAMIC ANALYSIS OF A PLAIN ANNULAR (LIQUID) SEAL IN THE LAMINAR REGIME WITH A SWIRL BRAKE FOR THREE CLEARANCES
}

\author{
Ovais Ahmed Bin Najeeb \\ Turbomachinery Laboratory \\ Texas A\&M University \\ College Station, TX 77843, USA
}

\author{
Dara W. Childs \\ Leland T. Jordan Professor of \\ Mechanical Engineering \\ Texas A\&M University \\ College Station, TX 77843, USA
}

\section{ABSTRACT}

Annular seals are non-contacting mechanical elements designed to reduce leakage between two areas of differing pressures such as between two impeller stages in a pump. Circumferential fluid rotation inside the annular liquid seals is the leading cause of pump rotordynamic instabilities. Swirl brakes have been shown to be effective in reducing fluid rotation at the inlet of the seal; thus reducing destabilizing forces in the seal. Data showing the effects of swirl brakes over a range of clearance-to-radius ratios in laminar fluid flow conditions are needed.

This study involves tests using a smooth seal with three radial clearances $C_{r}=127 \mu \mathrm{m}, 254 \mu \mathrm{m}, 381 \mu \mathrm{m}(1 \mathrm{X}, 2 \mathrm{X}$ and $3 \mathrm{X}$ respectively), an axial length of $45.72 \mathrm{~mm}$ (1.80 in) and a diameter of $101.6 \mathrm{~mm}$ (4.00 in). An insert was used to induce pre-swirl upstream of the seal. Swirl brakes (SBs) were used to reduce circumferential fluid flow at the seal inlet. Swirl brakes comprised 36 square cuts at the seal entrance with an axial depth of $5.08 \mathrm{~mm}(0.2 \mathrm{in})$, radial height of $6.35 \mathrm{~mm}(0.25 \mathrm{in})$ and circumferential width of $6.35 \mathrm{~mm}$ (0.25 in) each. The study produced static and rotordynamic data at $\omega=2,4,6,8 \mathrm{krpm}$, $\Delta P=2.07,4.14,6.21,8.27$ bar $(30,60,90,120 \mathrm{psi})$, and eccentricity ratios $\varepsilon_{0}=e_{0} / C_{r}=0.00,0.27,0.53$, and 0.80 . The test used ISO VG 46 oil at a range of $115-120^{\circ} \mathrm{F}$ to keep $\mathrm{f}$ the fluid flow laminar (Total $R e \leq 650$ ). Dynamic measurements included components of the following vectors (a) stator-rotor relative displacements, (b) acceleration and (c) applied dynamic force in the $X-Y$ coordinate system. Measurements were also compared to predictions from a code developed by Zirkelback and San Andrés [1].

SBs are shown to be effective in minimizing inlet fluid rotation at the $3 \mathrm{X}$ clearance but ineffective at the $1 \mathrm{X}$ and $2 \mathrm{X}$ clearance. When SBs are used with the $3 X$ clearance seal, the cross-coupled stiffness variables have the same sign meaning that the seal would have a WFR of zero and would not produce destabilizing forces on a pump rotor. However, at the $3 \mathrm{X}$ clearance, the smooth annular seal has a negative direct stiffness $K$ that could potentially "suck" the rotor into contact with the stator wall, along with dropping the natural frequency of the pump rotor, further reducing its dynamic stability. Most of the predictions agree well with the test data. Notable exceptions are the direct and cross-coupled stiffness coefficients for the $3 \mathrm{X}$ clearance. Predictions showed positive direct stiffness and opposite signs for the cross-coupled stiffness coefficients.

\section{NOMENCLATURE}

$C_{r} \quad$ Seal radial clearance [L]

$D \quad$ Seal diameter [L]

$F_{S} \quad$ Required applied static load [F]

$f_{t}, f_{r} \quad$ Seal reaction forces in $t$ and $r$ directions [F]

$k \quad$ Cross-coupled stiffness coefficient $\left[\mathrm{M} / \mathrm{T}^{2}\right\}$

$L \quad$ Seal axial length [L]

$\dot{Q} \quad$ Seal volumetric leakage rate $\left[\mathrm{L}^{3} / \mathrm{T}\right]$

$R \quad$ Shaft radius [L]

$\Delta P \quad$ Seal differential pressure $\left[\mathrm{F} / \mathrm{L}^{2}\right]$

$v_{i} \quad$ Inlet circumferential fluid velocity $[\mathrm{L} / \mathrm{T}]$

$v_{\text {insert }} \quad$ Fluid velocity leaving the pre-swirl insert $[\mathrm{L} / \mathrm{T}]$

$\varepsilon_{0} \quad$ Static eccentricity ratio [-]

$\omega \quad$ Rotor speed [1/T]

$1 \mathrm{X}, 2 \mathrm{X}, 3 \mathrm{X}$ New radial clearance, two times the new radial clearance and three times the new radial clearance [-]

$\phi \quad$ Attitude angle shown in figure 18.

\section{Subscripts}

$i, j \quad$ Interchangeable $X$ and $Y$ directions

$r, t \quad$ Radial and tangential components

\section{Abbreviations}

PSR Pre-swirl ratio, defined in Eq. (5)

SBs Swirl brakes

SSSB Smooth seal with swirl brakes

WFR Whirl frequency ratio 


\section{INTRODUCTION}

Pumps and compressors use annular seals to reduce leakage between regions of differing pressures. Annular seals are non-contacting; there is a clearance between the rotor and the seal stator.

Shaft centering forces are developed in annular seals by mainly two means, (1) the hydrodynamic effect (fluid rotation), and, (2) the Lomakin effect [2]. Starting with the hydrodynamic effect, the eccentric position of the shaft in the annulus produces a converging region where pressure is higher and a diverging region where pressure is lower. The difference in circumferential pressure distribution produces a shaft reaction force. The hydrodynamic effect is pronounced in hydrodynamic bearings where shear flow due to shaft rotation is dominant due to lower $C_{r} / R$ ratios. The hydrodynamic effect is discussed in detail by Pinkus and Sternlicht [3].

Figure 1 helps in explaining the Lomakin effect [2]. Initially, the rotor is centered in the seal. The high $\Delta P=$ $P_{\text {supplied }}-P_{\text {exit }}$ causes the fluid to accelerate at the inlet. This leads to a pressure drop at the seal entrance followed by a pressure drop through the seal due to wall friction. As the rotor is displaced from the center of the seal, the clearance at the top decreases, leading to lower axial velocity, lower Reynolds number, and higher friction factor. Whereas, the clearance at the bottom increases, which leads to higher axial velocity, higher Reynolds number, and lower friction factor. A combination of these factors results in an axial pressure distribution (shown as gray areas in FiG. 1) that leads to a resultant centering force, $F$.

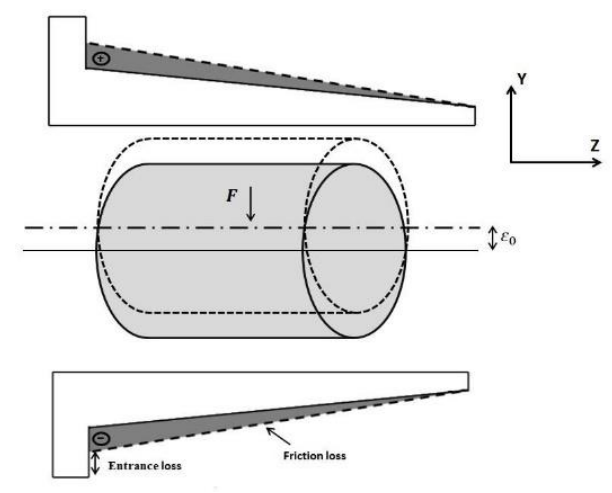

Figure 1. Lomakin effect.

The flow inside the seal can be stated in terms of an average circumferential component and an average axial component with a corresponding circumferential Reynolds number $\left(R e_{c}\right)$ and axial Reynolds number $\left(R e_{a}\right)$, respectively. Total Reynolds number, $R e_{t}$ refers to the resultant of $R e_{c}$ and $R e_{a}$. For an annular seal the hydraulic diameter is $2 C_{r}$. Hence,

$$
\begin{gathered}
R e_{c}=\frac{\rho R \omega C_{r}}{\mu} \\
R e_{a}=\frac{\rho 2\left(C_{r}\right) w}{\mu} \\
R e_{t}=\sqrt{R e_{a}^{2}+R e_{c}^{2}},
\end{gathered}
$$

where $\mu$ is lubricant viscosity and $w=\dot{Q} / 2 \pi R C_{r}$ is the average axial velocity. At tighter clearances and laminar flow conditions $\left(R e_{t}<1800\right)$, seals generally act more like bearings as fluid rotation effects dominate.

For Electric Submersible Pumps (ESPs), as the clearances increase, viscous forces due to fluid rotation decrease, and the Lomakin effect becomes more pronounced even when the fluid flow is laminar [4].

Instability in a rotor-bearing system is primarily caused by fluid rotation in the bearing/seal annulus [5]. Black et al. [6] were the first to analyze the effect of inlet pre-swirl of the fluid flow on the seals' rotordynamic characteristics. Figure 2 from Childs [5] shows the predicted WFR (WFR $=k / C \omega$ ) versus length to diameter ratio, $L / D$, of a seal $\left(C_{r} / R=0.005\right)$ with changing inlet pre-swirl. WFR drops as inlet/pre-swirl decrease. The cross coupling stiffness coefficient $k$ is also a function of the inlet pre-swirl, and it decreases as inlet swirl drops [5]. A lower WFR and $k$ thus would reduce the seal's ability to destabilize a pump.

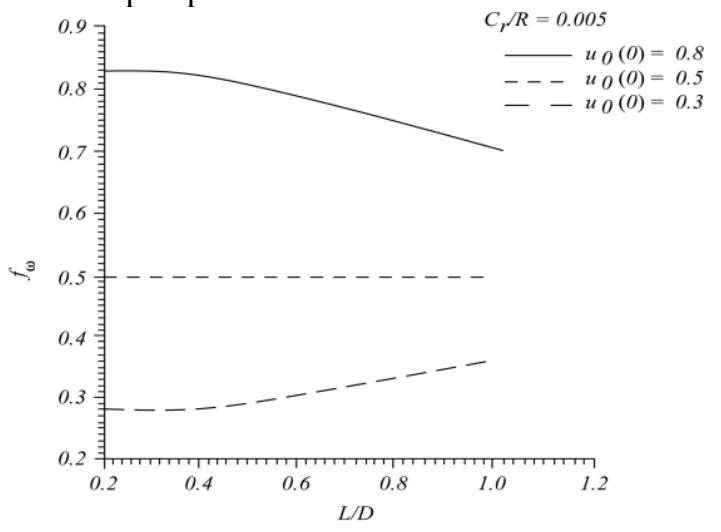

Figure 2. Effect of changing Inlet Swirl on WFR for a Smooth Seal [5].

SBs use a series of circumferential slots or webs at the seal inlet to lower the inlet pre-swirl of the fluid entering a seal. Benchert and Wachter [7] were the first to use SBs for gas labyrinth seals, referring to them as "swirl webs" to effectively reduce WFR and $k$.

Figure 3 shows an SB design used by Massey [8] to stabilize a pump. Massey's pump operated with a light hydrocarbon with low viscosity at elevated temperatures. It was unstable, and an SB at the balance-piston seal was required to stabilize it. SBs have been shown to be effective in machines handling low viscosity fluids such as Massey's pump. On the other hand, the effectiveness of installing SBs on seals operating with higher viscosity fluids is still uncertain. 

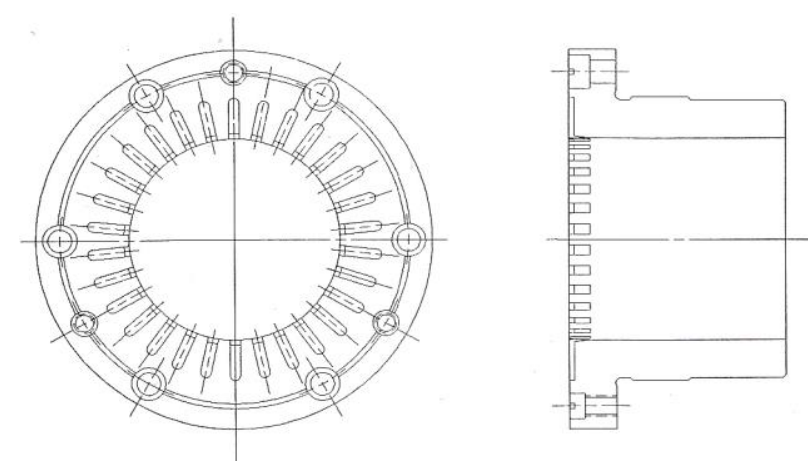

Figure 3. Balance-piston seal swirl brake [5].

With a high-viscosity liquid at low seal clearances, shear forces due to shaft rotation are large and overwhelm the inlet pre-swirl condition, and the bulk-flow circumferential velocity is $R \omega / 2$. SBs are predicted to be ineffective in these conditions. As clearance and leakage increase due to wear in a pump, the hydrodynamic effect becomes less effective, and the Lomakin effect becomes more important. Using predictions from the model of [1] for seal rotordynamic coefficients, Childs and Norrbin [4] predicted that SBs would be effective in improving the rotordynamic stability of seals in these enlarged-clearance circumstances. This study aims to experimentally investigate the predictions of seal rotordynamic coefficients of smooth seals with SBs, operating with a higher viscosity fluid at enlarged clearances.

This study presents measurements of the static and rotordynamic force coefficients for a smooth seal with swirl brakes (SSSB) for the first time in the laminar flow regime. Measurements are also compared to predictions by a code based on Zirkelback and San Andrés [1]. Additionally, imposed pre-swirl immediately upstream of swirl brake and outlet swirl are measured. The first author conducted this study as part of a Master's thesis at Texas A\&M University. Details of the literature review, test rig, testing procedure, data analysis, and results can be found in Ref. [9].

The test seals use SBs and are smooth with axial length $L=45.720 \mathrm{~mm} \quad(1.800$ in $)$ and clearances $C_{r}=$ $127 \mu \mathrm{m}, 254 \mu \mathrm{m}, 381 \mu \mathrm{m}$ ( $1 \mathrm{X}, 2 \mathrm{X}$ and $3 \mathrm{X}$ respectively). The corresponding radial clearance to radius ratios $\left(C_{r} / R\right)$ were $0.0025,0.005,0.0075$. The length to diameter ratio $(L / D)$ of the annular seal was 0.45 . Figure 4 presents a detailed drawing of the seal with SBs. Each SB has a total of 36 square cuts with axial length $D_{s b}=5.08 \mathrm{~mm}\left(0.2\right.$ in), radial height $H_{s b}=6.35 \mathrm{~mm}$ $(0.25 \mathrm{in})$ and circumferential width $W_{s b}=6.35 \mathrm{~mm}(0.25 \mathrm{in})$.
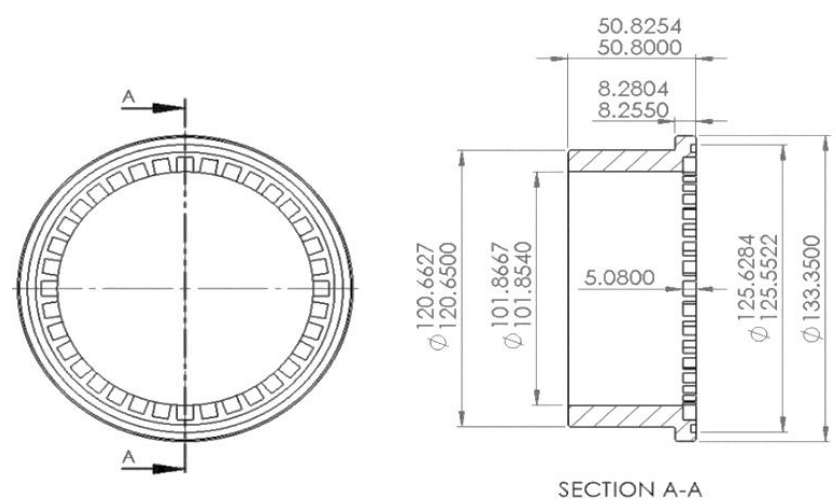

Figure 4. Detailed drawing of new clearance seal with swirl brakes. All dimensions are in $\mathbf{~ m m}$

The seal test matrix consists of 192 test points:

3 Clearances: $1 \mathrm{X}, 2 \mathrm{X}$ and $3 \mathrm{X}$,

4 running speeds: $2,4,6$, and $8 \mathrm{krpm}$,

4 axial pressure drops: $2.07,4.14,6.21$, and 8.27 bar,

4 eccentricity ratios: $0.00,0.27,0.53$, and 0.80 .

ISO VG 46 oil is used as the test fluid at a temperature range of $46.0-49.0^{\circ} \mathrm{C}$.

\section{TEST APPARATUS}

The test rig shown in Fig. 5 was used to conduct static and dynamic measurements of the SSSBs. It was initially designed by Kaul [10] to test annular oil bushing seals for compressors. "Ground" for the main test section is formed by mild steel plates that support the electric motor, the motor mount and the two pedestals.
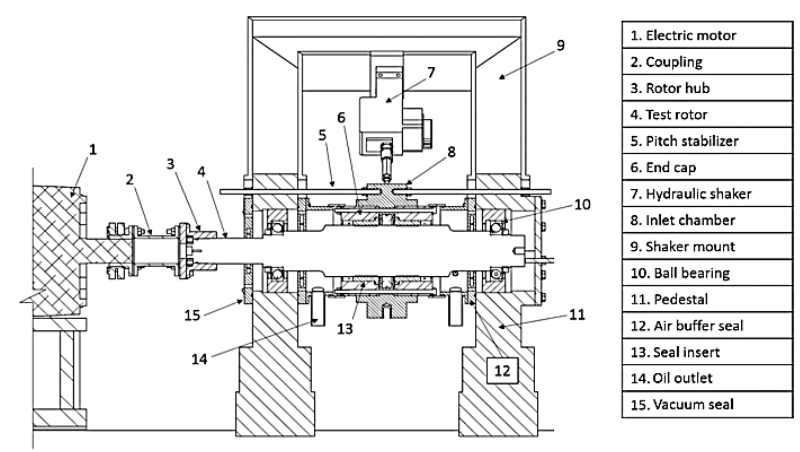

Figure 5. Cross-sectional view of the main test section.

The pedestal assemblies have an upper half and a lower half. The lower half supports angular contact ball bearings that in turn support the smooth rotor with a span of $640.1 \mathrm{~mm}(25.2$ in) and maximum diameter of $101.6 \mathrm{~mm}$ (4 in). The rotor is connected to the variable frequency drive $29.8 \mathrm{~kW}(40 \mathrm{hp})$ electric motor by the coupling. The rotor maximum speed is 8 $\mathrm{krpm}$. As shown in Fig. 5 and described in detail in [10], other peripherals that form the main test section include pitch stabilizers, collection chambers, an end cap, air buffer seals and vacuum seal. Pitch stabilizers are 6 long threaded bolts that are screwed between the pedestals and the stator to keep the stator 
parallel to the rotor [10]. The collection chambers collect the oil as it leaves the stator during testing. An end cap seals the non-drive end (NDE) of the main test section.

The upper half of the pedestal assembly contains the two hydraulic shaker assemblies. Shaker heads are connected to the stator via stingers as shown in Fig. 6. The hydraulic shaker assembly includes a load cell mounted on each of the orthogonal $X$ and $Y$ axes to measure the force applied in each direction. The shakers can excite the stator up to $1 \mathrm{kHz}$ and provide a maximum tension and compression of $4450 \mathrm{~N}$.

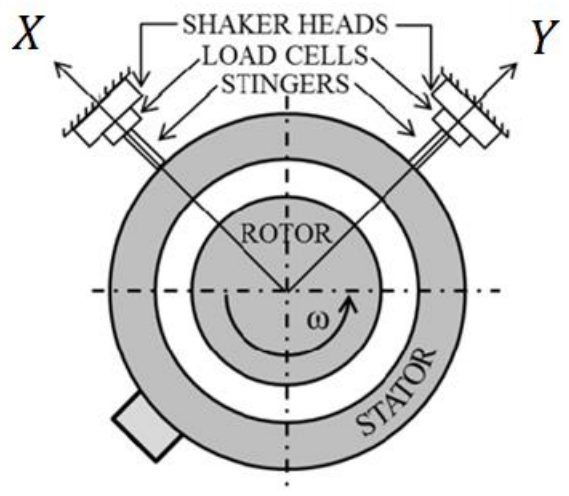

Figure 6. Drive Side (DS) view of the shaker assembly. Adapted from [10].

Figure 7 is a photo of the $1 \mathrm{X}$ clearance test seal. The SB design is inspired from Massey's SB design [8] as shown previously in Fig. 3. Its rugged construction would resist wear due to particulates in the flow. A better design for inlet circumferential flow control could probably be developed using CFD. With the data provided in this study, the design could be further improved using CFD analysis.

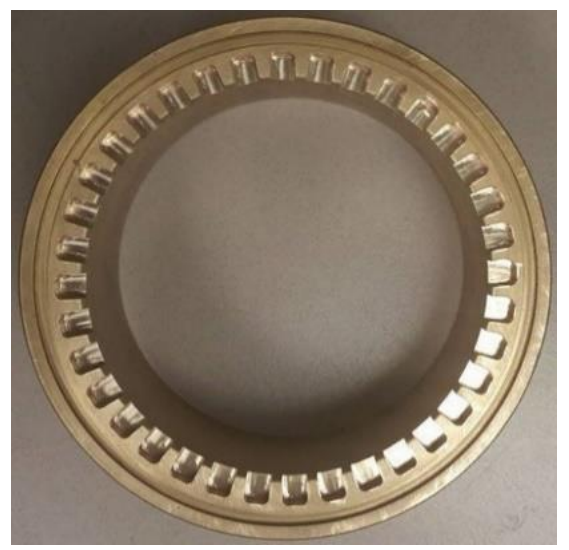

Figure 7. 1X clearance seal with SBs.

Figure 8 shows the insert used to induce pre-swirl. The insert has 12 nozzles. Each nozzle has a diameter of $4.039 \mathrm{~mm}$ (0.1590 in). It was designed to produce inlet pre-swirl ratio (defined in Eq. (5)) ranging from 0-0.8 depending on rotor speed and $\Delta P$. Note that the injection angle is such that the fluid stream leaving the pre-swirl insert nozzles is tangential to the rotor surface as shown in Fig. 8.

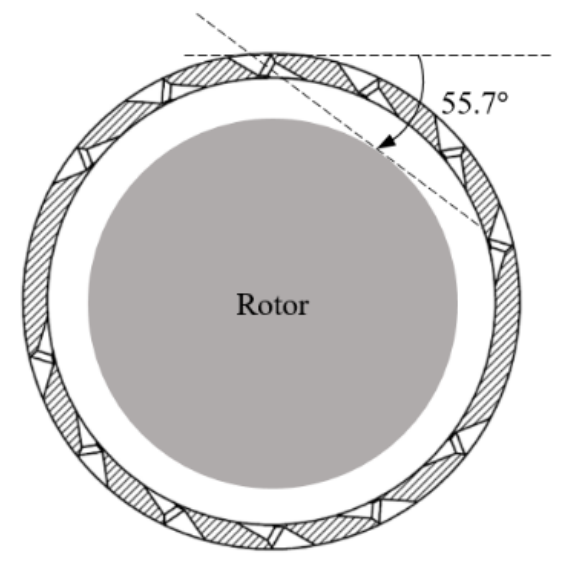

Figure 8. Cross-sectional view of high pre-swirl insert.

As shown in Fig. 9, the stator assembly consists of the following three main parts: inlet chamber, seal holders, and SSSBs. The pre-swirl insert described above is part of the inlet chamber. SSSBs are press fitted into a set of seal holders that are in turn assembled into the inlet chamber.

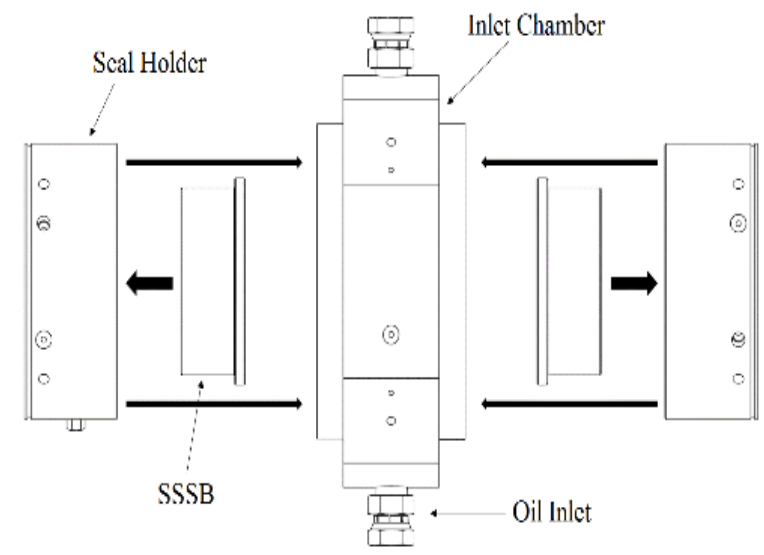

Figure 9. Stator assembly schematic.

Figure 10 shows the test-fluid flow path. After passing through the pre-swirl insert, the swirling fluid is then met by the SBs. Oil then enters the seals and eventually leaves the stator into the collection chambers. Note that a labyrinth tooth at the end of the seal holder is present to avoid cavitation at the seal's exit. 


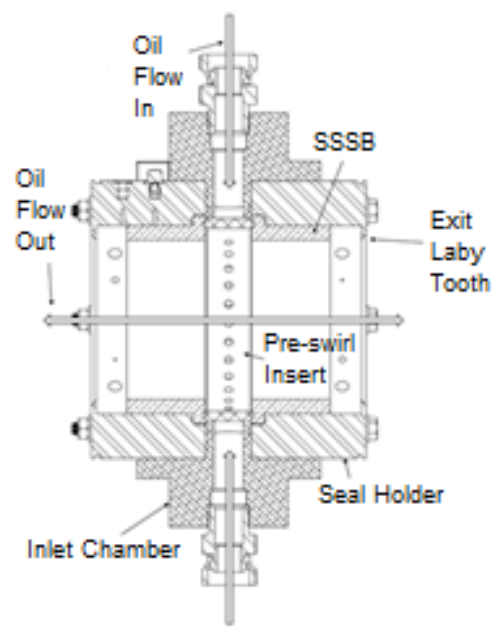

Figure 10. Stator and lubricant flow path.

The instrumentation shown in Fig. 11 was used to measure the dynamic and static characteristics of the test rig.

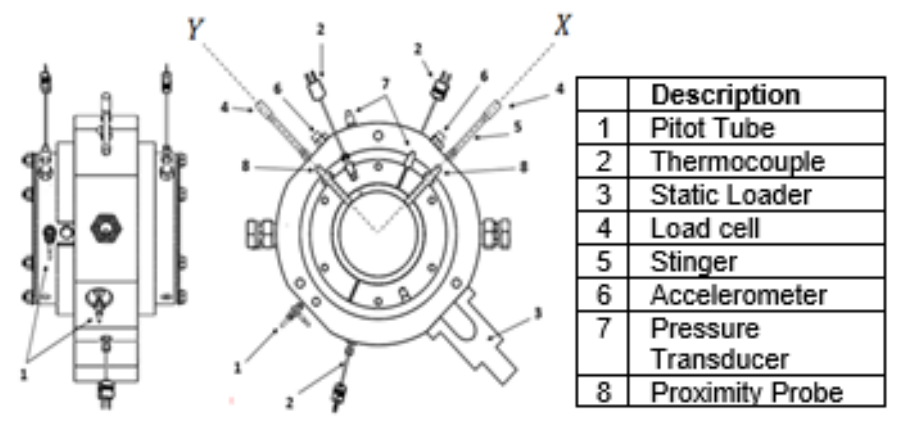

Figure 11. Assembled stator and instrumentation.

\section{STATIC TEST PROCEDURE}

Prior to tests, the "Cold" clearance of the seal is measured without any oil in the system at zero $\omega$. Cold refers to the measurement that is taken at room temperature. As shown in Fig. 11, Four-eddy current sensors, located orthogonally in two different axial planes, measure the gaps between the seal and rotor (radial clearance). To measure the clearance circle, the seal housing is forced to touch the rotor with an applied force from the hydraulic shakers. The housing is then precessed $360^{\circ}$ around the rotor by adjusting the force from $X$ and $Y$ shaker units while maintaining a contact force. Continuous acquisition of the clearance data throughout this process captures the clearance circle of the test seal. The cold-clearance circle also locates the geometric center of the seal.

The operator supplies oil to the test-rig oil until (using a heater) the lubricant temperature reaches a steady test condition of $46.1^{\circ} \mathrm{C}\left(115 \pm 5^{\circ} \mathrm{F}\right)$. At this point, oil flow is stopped, and the clearance circle is immediately measured. This clearance circle is the "hot" clearance circle. It is smaller than the cold clearance circle due to thermal expansion. The hot clearance is used to calculate the eccentricity ratios.
At each steady-state condition, sensors are used to measure the following parameters: $\omega, \Delta \mathrm{P}$, eccentricity $\left(e_{0}\right.$, relative rotor position in the $X$ and $Y$ coordinate system), inlet and outlet temperatures, Leakage $(\dot{Q})$, and applied static load $\left(F_{S}\right)$. Note that the measured values of $\dot{Q}$ and $F_{s}$ are for both of the backto-back test seals. They need to halved to get values for each seal.

\section{STATIC RESULTS}

\section{Leakage}

Figure 12 shows predicted and measured $\dot{Q}$ versus $\varepsilon_{0}$ at (a) $\Delta \mathrm{P}=2.07$ and (b) $\Delta \mathrm{P}=8.27$ bar and for all clearances. An inhouse code, XLanSeal ${ }^{\circledR}$ based on a model discussed in [1] is used for predictions. Note that $\operatorname{Exp} X$ and XLan $X$ in the graph refer to measured and predicted $\dot{Q}$ for the $1 \mathrm{X}$ clearance seal, respectively, and the naming convention is repeated for the $2 \mathrm{X}$ and $3 \mathrm{X}$ clearance seal. Uncertainty values are very small compared to measured data and are difficult to see in the figure. As expected, $\dot{Q}$ increases as $C_{r}$ and $\Delta P$ increase. $\dot{Q}$ is predicted well for the $1 \mathrm{X}$ and the $2 \mathrm{X}$ clearance seals. However, measured $\dot{Q}$ is 1.25 times higher than predicted $\dot{Q}$ for the $3 \mathrm{X}$ clearance seal.

Note that $\Delta P$ was obtained using a pressure measured upstream of the SBs and not immediately upstream of the seal inlet. The same $\Delta P$ was used to predict $\dot{Q}$ across the seal. The $\dot{Q}$ discrepancy between measurements and predictions could be due to the SBs converting the velocity head due to circumferential flow into a pressure head, thereby increasing the $\Delta \mathrm{P}$ across the seal. However, assuming that the inlet circumferential velocity head $\rho v_{i}^{2} / 2$ is converted to pressure, the $\dot{Q}$ predictions for the 3 X clearance seal do not significantly improve.

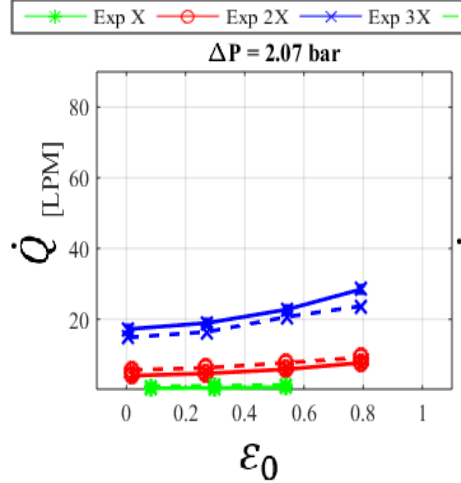

(a)

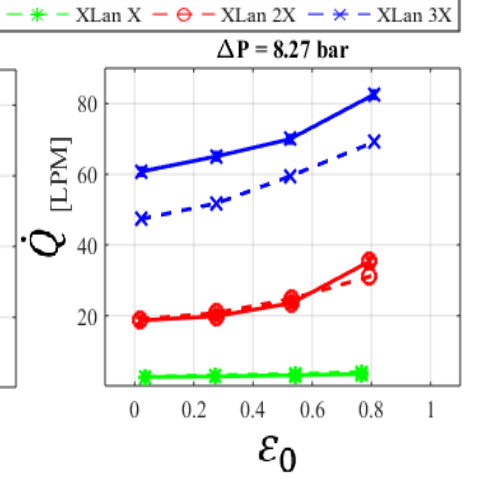

(b)
Figure 12. Measured and predicted $\dot{Q}$ versus $\varepsilon_{0}$ for $\omega=6$ krpm at (a) $\Delta P=2.07$ bar, and (b) $\Delta P=8.27$ bar.

\section{Pre-swirl Ratio}

Two pitot tubes measure the dynamic and static pressure at the inlet and outlet of the liquid annular seal. They are used to 
calculate the inlet and outlet circumferential velocities $\left(v_{i}\right.$ and $\left.v_{o}\right)$, respectively at specific locations. The defining equation is

$$
v=\sqrt{\frac{2 \Delta P_{\text {pitot }}}{\rho}}
$$

where $\Delta P_{\text {pitot }}$ is the pressure difference between the static and dynamic pressure measurements, and $\rho$ is the fluid density. The swirl ratio is the ratio of the fluid inlet circumferential velocity to the rotor's surface speed. The pre-swirl ratio (PSR) is

$$
P S R=\frac{v_{i}}{\omega R}
$$

Figure 13a shows the axial positions of the inlet and outlet pitot tubes. Figure 13b shows an enlarged axial view of the inlet pitot tube.

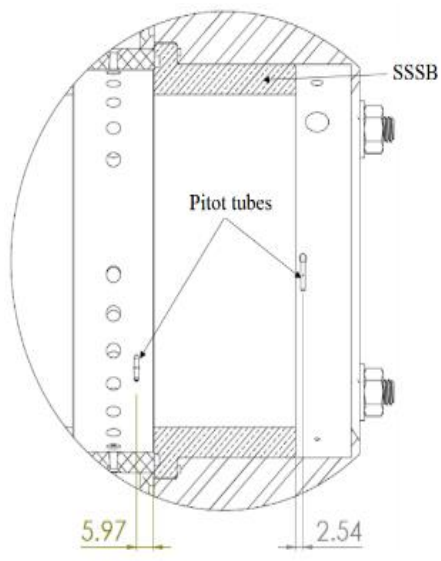

(a)

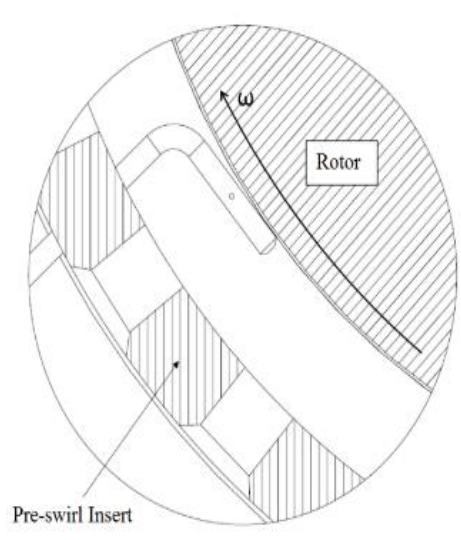

(b)
Figure 13. (a) Axial positions of the pitot tubes. (b) Radial view of the inlet pitot tube location. All dimensions in $\mathbf{~ m m}$. Adapted from [11].

Figure 14 shows the location of the pre-swirl pitot tube. Note that the radial location of the pre-swirl pitot tube differs for each of the SSSBs. The pre-swirl pitot-tube radial clearance always equals the radial clearance $C_{r}$ of the seal; specifically $0.127,0.254$ and $0.381 \mathrm{~mm}$ for $1 \mathrm{X}, 2 \mathrm{X}$ and $3 \mathrm{X} C_{r}$, respectively.

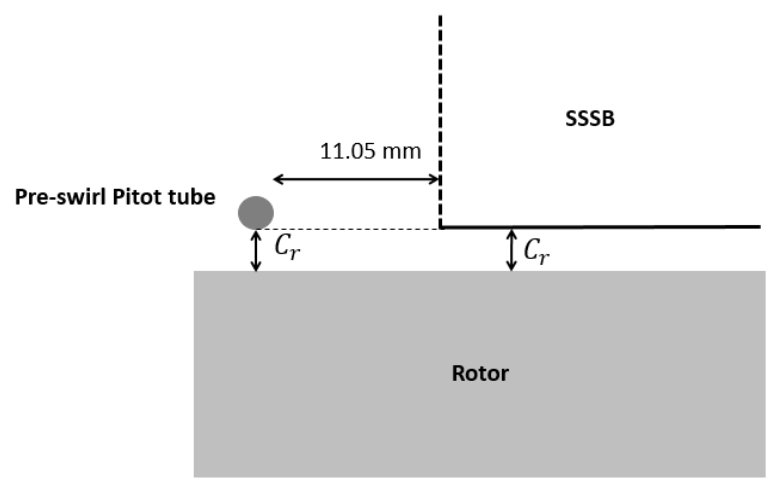

Figure 14. Radial position of the inlet pre-swirl pitot tube. Note that the Figure is not drawn to scale.
Figure 15 shows the measured inlet circumferential velocity $v_{i}$ versus $\omega$ for a range of $\Delta \mathrm{P}$. The solid lines represent measured $v_{i}$. The dashed lines represent the fluid velocity leaving the pre-swirl insert, $v_{\text {insert }}$ calculated as follows

$$
v_{\text {insert }}=\frac{\dot{Q}}{12 \pi r_{\text {nozzle }}^{2}}
$$

where $r_{\text {nozzle }}$ is the radius of each hole in the pre-swirl insert.

The darkest line represents $R \omega$, the fluid circumferential velocity at the rotor surface assuming no slip conditions. Figure 15 shows that $v_{i}$ increases as $\omega$ and $\Delta \mathrm{P}$ increase for all the clearances. The $v_{i}$ magnitudes are higher than $v_{\text {insert }}$, especially for the $2 \mathrm{X}$ and the $3 \mathrm{X}$ clearance seals. For the $3 \mathrm{X}$ clearance seal, $v_{\text {insert }}$ is higher than $v_{i}$ at $\omega=$ $2 \mathrm{krpm}$ and all $\Delta$ Ps. The data of Fig. 15 shows a slight relationship between $v_{\text {insert }}$ and $v_{i}$ to the extent that generally $v_{i}(3 \mathrm{X})>v_{i}(2 \mathrm{X})>v_{i}(1 \mathrm{X})$ but changes in $\omega$ have a clear impact on $v_{i}$. One explanation for this impact is the induced circumferential flow due to shaft rotation, particularly with the high fluid viscosity used here. Another possible explanation could be the location of the pitot tube. As $C_{r}$ increases, the distance between the pitot tube and the rotor also increases (refer to Fig. 14). Thus the fluid velocity measurement location changes from seal to seal. $v_{i}$ does increase with increasing $\omega$ indicating an induced pre-swirl due to shearing force from the shaft rotation. As $\Delta P$ increases, $v_{i}$ tends to trend more with $v_{\text {insert }}$ and less with $R \omega . v_{i}$ is closer to the average fluid circumferential velocity $(R \omega / 2)$ for the $3 \mathrm{X}$ clearance seal.

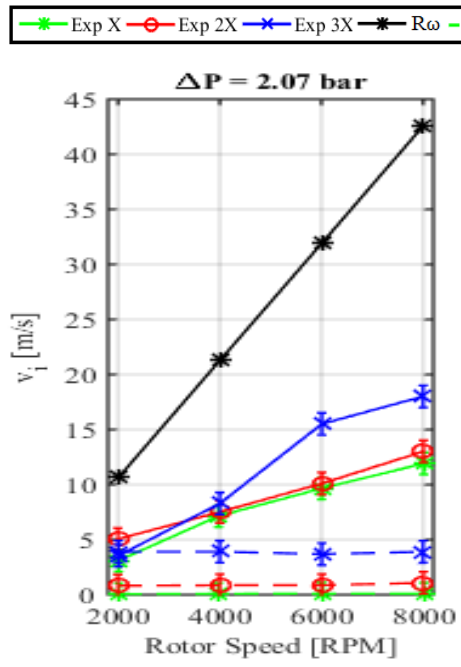

(a)

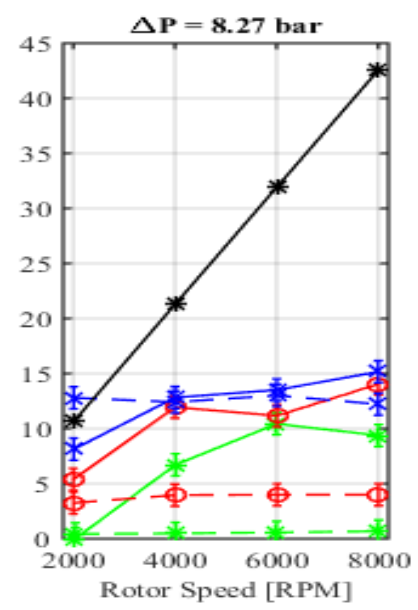

(b)
Figure 15. $v_{i}$ versus $\omega$ at $\varepsilon_{0}=0.00$ and (a) $\Delta P=2.07$ bar and (b) $\Delta P=8.27$ bar.

Figure 16 shows PSR versus $\omega$ at the centered position. As expected from Eq. (5), PSR generally decreases with increasing $\omega$ for all the seal clearances even though Fig. 15 shows $v_{i}$ increasing as $\omega$ increases. 


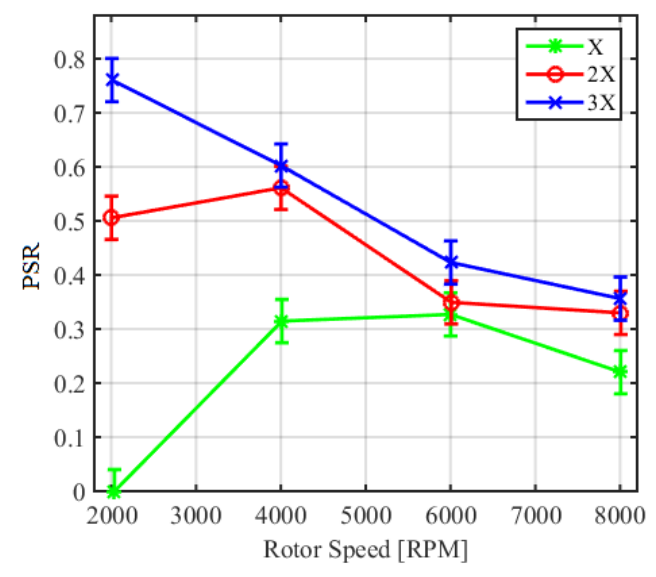

Figure 16. $P S R$ versus $\omega$ at $\Delta P=8.27$ bar.

\section{LOAD AND POSITION CONTROL}

Dynamic measurements at various eccentricity ratios can be set from the test rig in the following two modes: (a) Load Control, (b) Position control. As shown in Fig. 17a, load control refers to a force $F_{s}$ being applied by the shaker to the stator in the $-Y$ direction with no force being applied through the $X$-axis to achieve a specified $\varepsilon_{0}$. Alternatively, as shown in Fig. $17 \mathrm{~b}$, to achieve a specified $\varepsilon_{0}$, the shaker heads are used directly to position the stator along the $Y$ axis by applying forces from both shaker heads. The basic aim is to get the same $\varepsilon_{0}$ using either scheme. Most of the seals can be tested in the load-control mode as the seal-rotor system achieves an equilibrium position at a certain $\varepsilon_{0}$ and $F_{s}$. For some conditions, testing cannot be performed in load-control as the seal becomes statically unstable. However, such seals can be tested using the shakers in position control. The shakers in the $X$ and $Y$ direction provide the force components that are required to keep the stator in a specified eccentric position.

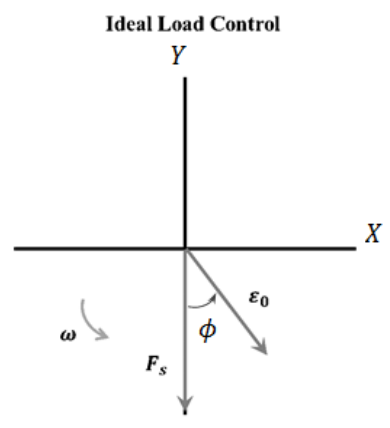

(a)

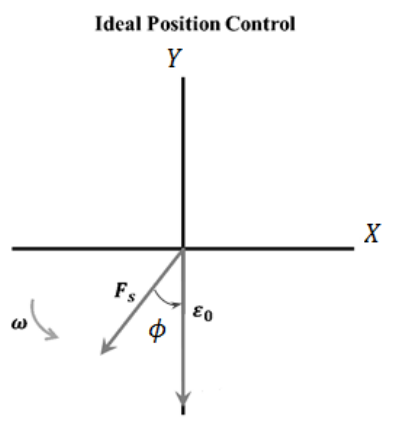

(b)
Figure 17. (a) Ideal load control, (b) Ideal position control.

The $1 \mathrm{X}$ and $2 \mathrm{X}$ clearance seals were tested in loadcontrol. The 3X clearance seal was tested in position control. To compare the $1 \mathrm{X}, 2 \mathrm{X}$ and $3 \mathrm{X}$ clearance seal resuts, the auhors used the $\boldsymbol{\epsilon}_{\boldsymbol{r}}$ and $\boldsymbol{\epsilon}_{\boldsymbol{t}}$ coordinate system. As shown in Fig. 18, the eccentricity vector is always in the $\boldsymbol{\epsilon}_{\boldsymbol{r}}$ direction.

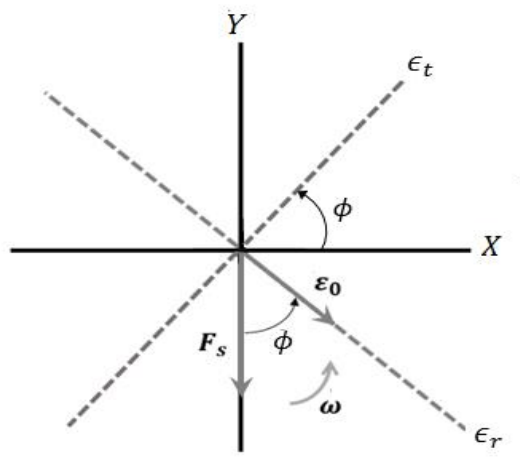

Figure 18. Coordinate transformation from cartesian coordinate system to $\boldsymbol{r}$ and $\boldsymbol{t}$ coordinate system.

The following similarity transformation is used to transform dynamic- coefficients in the $X-Y$ cartesian coordinate system to the $r$ - $t$ system.

$\left[\begin{array}{ll}Z_{t t} & Z_{t r} \\ Z_{r t} & Z_{r r}\end{array}\right]=$
$\left[\begin{array}{cc}\cos \phi & \sin \phi \\ -\sin \phi & \cos \phi\end{array}\right]\left[\begin{array}{ll}Z_{X X} & Z_{X Y} \\ Z_{Y X} & Z_{Y Y}\end{array}\right]\left[\begin{array}{cc}\cos \phi & -\sin \phi \\ \sin \phi & \cos \phi\end{array}\right]$

where $\phi$, illustrated in Fig.18, is the angle between the $\boldsymbol{F}_{\boldsymbol{s}}$ and $\varepsilon_{0}$ vector. The transformation applies to the $[\mathrm{K}],[\mathrm{C}]$, and $[\mathrm{M}]$ matrices. The rotordynamic model using the $\boldsymbol{\epsilon}_{\boldsymbol{t}}$ and $\boldsymbol{\epsilon}_{\boldsymbol{r}}$ coordinate system is

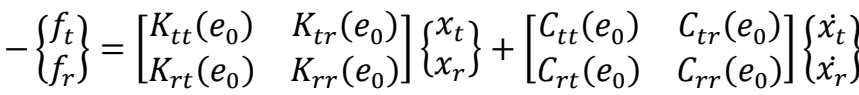

$$
\begin{aligned}
& +\left[\begin{array}{ll}
M_{t t}\left(e_{0}\right) & M_{t r}\left(e_{0}\right) \\
M_{r t}\left(e_{0}\right) & M_{r r}\left(e_{0}\right)
\end{array}\right]\left\{\begin{array}{c}
\ddot{x}_{t} \\
\ddot{x_{r}}
\end{array}\right\}
\end{aligned}
$$

\section{Required Applied Static Load and Attitude Angle}

Figure 19a shows measured attitude angle $\phi$ versus $\varepsilon_{0}$ at $\omega$ $=8 \mathrm{krpm}$ and $\Delta P=2.07$ bar. At $\varepsilon_{0}=0.00, \phi$ could not be determined because both the force and eccentricity vectors were zero. As expected, for the $1 \mathrm{X}$ clearance seal at $\varepsilon_{0}=0.27$, $\phi \geq 90^{\circ}$ is an indication that fluid inertia effects are important [12]. Destabilizing circumferential forces exist, and there is presence of decentering forces. As expected, for the $1 \mathrm{X}$ seal, $\phi$ generally decreases as $\varepsilon_{0}$ increases. At $\varepsilon_{0}>0.27, \phi$ is less than $90^{\circ}$, suggesting a positive centering force and a transverse force in the $\omega$ direction. For the $2 \mathrm{X}$ clearance seal at $\varepsilon_{0}=0.27, \phi \cong$ $90^{\circ}$. In such a situation, no centering force component exists; only a destabilizing force component exists. $\phi$ decreases as $\varepsilon_{0}$ increases and remains unaffected by a change in $\triangle \mathrm{P}$. For the $3 \mathrm{X}$ clearance seal, $\phi \cong 180^{\circ}$ at $\varepsilon_{0}=0.27,0.53$, implying that there is no forward circumferential destabilizing force, and that the centering force is negative. $\phi<90^{\circ}$ for all other test conditions.

Figure $19 \mathrm{~b}$ shows the measured and predicted static load $F_{s}$ required to produce each specified $\varepsilon_{0}$ for all clearances and $\Delta$ Ps. While testing in load control, the load $F_{S}$ is increased to 
achieve a specified $\varepsilon_{0}$; hence, for the $1 \mathrm{X}$ and $2 \mathrm{X}$ clearance seals, required $F_{S}$ is a function of $\varepsilon_{0}$ not vice versa. $F_{S}$ increases as $\varepsilon_{0}$ increases and $C_{r}$ decreases. There is generally good agreement between predictions and measurements. However for the $1 \mathrm{X}$ clearance seal at $\varepsilon_{0}=0.80$, measured $F_{S}$ is consistently larger than predicted. For the $3 \mathrm{X}$ clearance at $\varepsilon_{0}=$ $0.23,0.57$ at $\Delta \mathrm{P}=2.07$ bar and $\omega=8 \mathrm{krpm}$, measured $F_{s}$ is negative. This outcome agrees with the $\phi=180^{\circ}$ results shown in Fig. 19a. Direct stiffness would be expected to be negative in these cases. The model fails to predict negative $F_{S}$ at $\varepsilon_{0}=0.23$, 0.57 at $\Delta \mathrm{P}=2.07$ bar and $\omega=8 \mathrm{krpm}$. Note that the uncertainties are small and difficult to see in the figure.

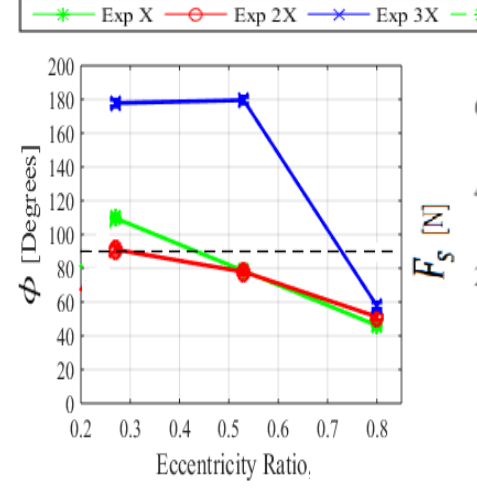

(a)

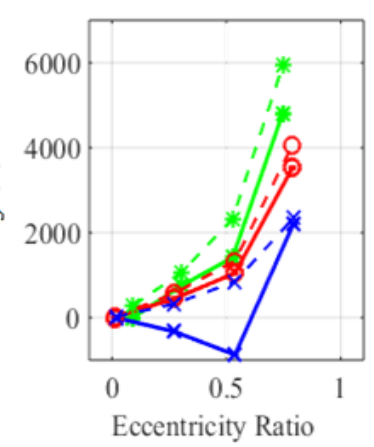

(b)
Figure 19. $\omega=8 \mathrm{krpm}$ and $\Delta P=2.07$ bar (a) Measured $\phi$ versus $\varepsilon_{0}$, (b) Measured $F_{s}$ versus $\varepsilon_{0}$.

\section{ROTORDYNAMIC - COEFFICIENT PARAMETER IDENTIFICATION}

The multiple-frequency-excitation method employed by Rouvas and Childs [13], and Childs and Hale [14] was used here to measure the seal dynamic-stiffness coefficients. The input shake frequency is a pseudo random waveform optimized to provide maximum excitation at a range of frequencies between $\sim 10-200 \mathrm{~Hz}$. The stator acceleration components, relative rotor stator displacement components, and applied dynamic load components are measured as the hydraulic shakers excite the stator in each of the orthogonal $(X \& Y)$ directions. The force, acceleration, and relative-displacement data components obtained in the time domain are transformed into the frequency domain using the fast Fourier transform (FFT) method. The real and imaginary parts of the complex frequency response function, $\boldsymbol{H}_{\boldsymbol{i} j}$ can be related to the stiffness, damping and virtual-mass coefficients by

$$
\boldsymbol{H}_{i j}=\left(K_{i j}-\Omega^{2} M_{i j}\right)+\boldsymbol{j}\left(\Omega C_{i j}\right)
$$

where $\Omega$ is the excitation frequency and $\boldsymbol{j}$ is $\sqrt{-1}$. Next, leastsquares regression curve fits are applied to the real and imaginary parts of the complex frequency response function. The coefficients from these curve fits produce the stiffness, damping and virtual mass terms. For repeatability calculations, a $95 \%$ confidence interval is used. Confidence intervals for the rotordynamic coefficients are calculated using a statistical test described in Ref. [15].

The next step involves separately measuring the "dry" baseline characteristics of the test-rig including seal housing and additional supporting structures of the test-rig. The measurements utilize the "floating stator" method developed by Gilienicke [16]. Actual dynamic measurements include both the annular fluid reaction forces and the reactions from the test rig itself. To isolate the dynamic stiffness of the seals and the test rig, the operator applies dynamic excitations to the stator with no oil running through the test rig. These dry baseline results are then subtracted from the measured dynamic stiffness while testing with lubricant resulting solely in the fluid-film dynamic stiffness.

\section{DYNAMIC RESULTS}

\section{Stiffness Coefficients}

Figure 20 shows $K_{t t}$ and $K_{r r}$ versus $\varepsilon_{0}$ at $\Delta P=2.07$ bar and $\omega=4 \mathrm{krpm}$. As expected, at higher $\varepsilon_{0}$ values, $K_{r r}$ is greater than $K_{t t}$, since the rotor has been displaced in the $\varepsilon_{0}$ direction, and the rotor is closer to the seal wall in the $r$ direction. $K_{t t}$ and $K_{r r}$ increase as $\varepsilon_{0}$ increases for all clearances. $K_{t t}$ and $K_{r r}$ decrease as clearance increases. $K_{r r}$ is well predicted for the $1 \mathrm{X}$ and $2 \mathrm{X}$ clearance seal up to $\varepsilon_{0}=0.53$. At $\varepsilon_{0}=0.80, K_{r r}$ is $20 \%$ greater than predicted for the $1 \mathrm{X}$ clearance seal. $K_{t t}$ is well predicted for the $1 \mathrm{X}$ and $2 \mathrm{X}$ clearance seal up to $\varepsilon_{0}=0.53$. At $\varepsilon_{0}=0.80, K_{t t}$ is $20 \%$ greater than predicted for the $3 \mathrm{X}$ clearance seal. Also, at $\varepsilon_{0}=0.80$, measured $K_{t t}$ is $50 \%$ greater than predicted for the $2 \mathrm{X}$ clearance seal.

Interestingly, measured $K_{t t}$ and $K_{r r}$ are negative at all eccentricity ratios for the $3 \mathrm{X}$ clearance seal. This seems to explain why it was difficult to hold the $3 \mathrm{X}$ clearance seal in the load-control mode. A negative stiffness would mean that the test rotor would be "sucked in" towards the stator wall. However, the model [1] predicts positive $K_{t t}$ and $K_{r r}$ for the $3 \mathrm{X}$ clearance seal. Predicted $K_{t t}$ and $K_{r r}$ are slightly positive for the $3 \mathrm{X}$ clearance at all eccentricity ratios.

For the $3 \mathrm{X}$ seal, recall that $F_{s}$ was negative at $\varepsilon_{0}=0.27$, $0.53, \Delta \mathrm{P}=2.07$ bar and $\omega=8 \mathrm{krpm}$. This suggested that $K_{r r}$ would also be negative. Measured $K_{r r}$ is negative at these conditions. However, $\phi<90^{\circ}$ for Fig. 17a at $\varepsilon_{0}=0.80$ implied a positive $K_{r r}$ versus the negative $K_{r r}$ shown in Fig. 20. 


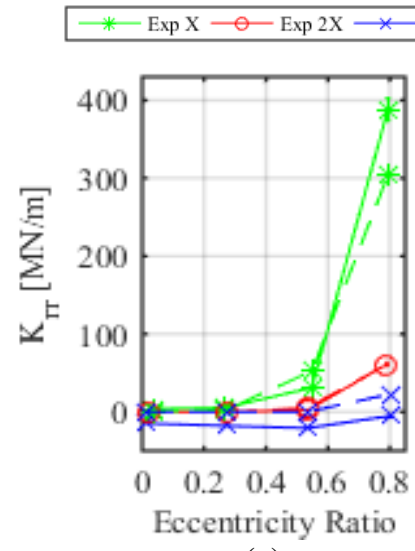

(a)

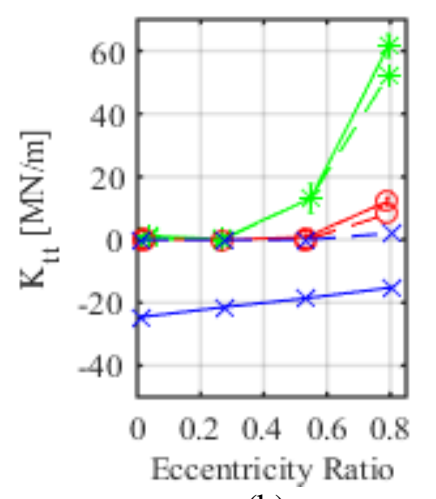

(b)
Figure 20. $\Delta P=2.07$ bar and $\omega=4 \mathrm{krpm}$ (a) Measured and predicted $K_{r r}$ versus $\varepsilon_{0}$. (b) Measured and predicted $K_{t t}$ versus $\varepsilon_{0}$.

Figure 21a shows measured $K_{t r}$ and $K_{r t}$ versus $\varepsilon_{0}$ at $\Delta P=$ 2.07 bar and $\omega=4 \mathrm{krpm}$. For $1 \mathrm{X}$ and $2 \mathrm{X}$ clearance seals, $K_{r t} \cong$ $-K_{t r}$ indicating strong destabilizing characteristics. Increasing the clearance from $1 \mathrm{X}$ to $2 \mathrm{X}$ decreases the cross-coupled stiffness. Increasing from $2 \mathrm{X}$ to $3 \mathrm{X}$ causes both $K_{t r}$ and $K_{r t}$ to become positive and no longer destabilizing; hence, the SBs are effective at the $3 \mathrm{X}$ clearance.

Figure $21 \mathrm{~b}$ shows predicted $K_{t r}$ and $K_{r t}$ versus $\varepsilon_{0}$. The predictions agree well with test data for $1 \mathrm{X}$ and $2 \mathrm{X}$ clearance seals. For the $3 \mathrm{X}$ clearance seal, the model predicts different signs for $K_{t r}$ and $K_{r t}$ that could destabilize the pump. Measurements show that $K_{t r}$ and $K_{r t}$ are both positive, thus not destabilizing.

However, recall that measured $K_{t t}$ and $K_{r r}$ are negative at the $3 \mathrm{X}$ clearance. The $3 \mathrm{X}$ clearance seal 's negative direct stiffness coefficients would drop the pump's natural frequency, which would tend (by itself) to destabilize the pump rotor due to destabilizing forces of the impellers and other seals.

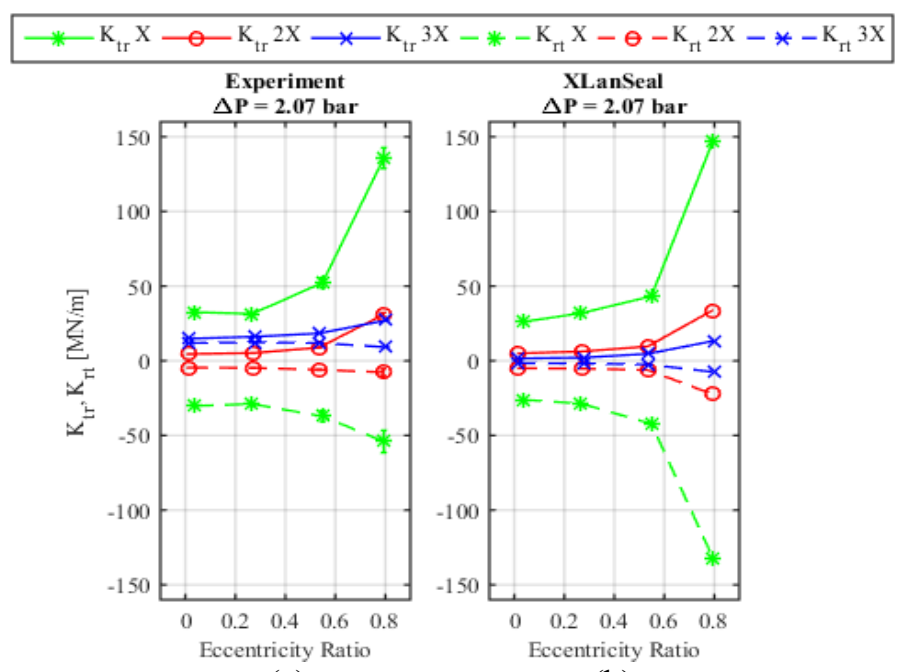

(a)

Figure 21. $\Delta P=2.07$ bar and $\omega=4 \mathrm{krpm}$ (a) Measured $K_{t r}$ and $K_{r t}$ versus $\varepsilon_{0}$. (b) Predicted $K_{t r}$ and $K_{r t}$ versus $\varepsilon_{0}$.

\section{Damping Coefficients}

Figure 22 show $C_{t t}$ and $C_{r r}$ versus $\varepsilon_{0}$ at $\Delta P=2.07$ bar and $\omega=2 \mathrm{krpm}$ for all clearances. $C_{r r}$ increases as $\varepsilon_{0}$ increases and $C_{r}$ decreases. Note that for $\varepsilon_{0}>0.00, C_{r r}$ is greater than $C_{t t}$ since the rotor is moving closer to the seal wall in the $r$ direction. $C_{t t}$ and $C_{r r}$ remain close to each other up to $\varepsilon_{0}=0.27$ and then start to diverge for all clearances. $C_{r r}$ increases as $\varepsilon_{0}$ increases for all clearances. The predictions match the measurements very well for the $2 \mathrm{X}$ and $3 \mathrm{X}$ seals and the $1 \mathrm{X}$ seal out to $\varepsilon_{0} \leq 0.57$. However, for the $1 \mathrm{X}$ clearance seal, predicted damping is markedly higher than measured at $\varepsilon_{0}=$ 0.80 . For the $1 \mathrm{X}$ clearance seal, $C_{t t}$ decreases up to $\varepsilon_{0}=0.51$ and then increases. The predictions follow the same trend but the predicted magnitude is higher. For the $2 \mathrm{X}$ and $3 \mathrm{X}$ clearance seals, $C_{t t}$ increases as $\varepsilon_{0}$ increases, and the predictions closely match the measurements.

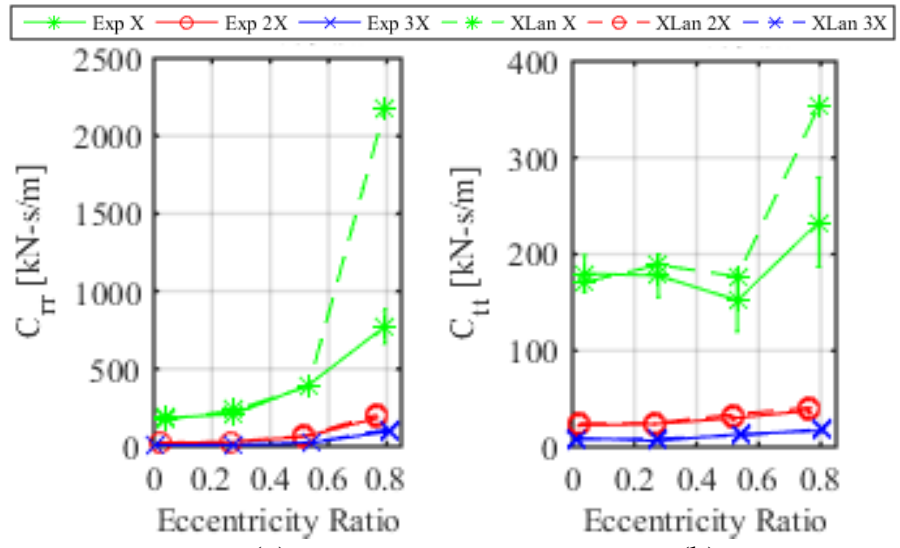

(a)

Figure 22. $\Delta P=2.07$ bar and $\omega=2 \mathrm{krpm}$ (a) Measured and Predicted $C_{r r}$ versus $\varepsilon_{0}$. (b) Measured and Predicted $C_{t t}$ versus $\varepsilon_{0}$. 
Figure 23a shows measured and predicted $C_{t r}$ versus $\varepsilon_{0}$ for all clearances at $\Delta P=6.21 \mathrm{bar}$ and $\omega=4 \mathrm{krpm}$. Measured and predicted $C_{t r}$ remain close to zero up to $\varepsilon_{0}=0.53$ and increases at $\varepsilon_{0}=0.80$ for all clearances. For the $1 \mathrm{X}$ clearance seal, predicted $C_{t r}$ is larger than measured by about 5 times. For the $2 \mathrm{X}$ clearance seal at $\varepsilon_{0}>0.27$, predicted $C_{t r}$ is larger than measured by about $10 \%$. Predictions match measurements well for the $3 \mathrm{X}$ clearance seal.

Figure 23b shows $C_{r t}$ versus $\varepsilon_{0}$. Measured and predicted $C_{r t}$ remains close to zero up to $\varepsilon_{0}=0.53$ and increases at $\varepsilon_{0}=$ 0.80 for all the three clearance seals. For the $1 \mathrm{X}$ clearance seal, predicted $C_{t r}$ is larger than measured by about 2 times. For the $2 \mathrm{X}$ clearance seal at $\varepsilon_{0}>0.27$ predicted $C_{t r}$ is larger than measured by about $10 \%$. Predictions match measurements well for the $3 \mathrm{X}$ clearance seal. Note that, for most of the test points $C_{t r}$ and $C_{r t}$ have the same sign. Therefore, they act as real dissipative damping and not gyroscopic damping.

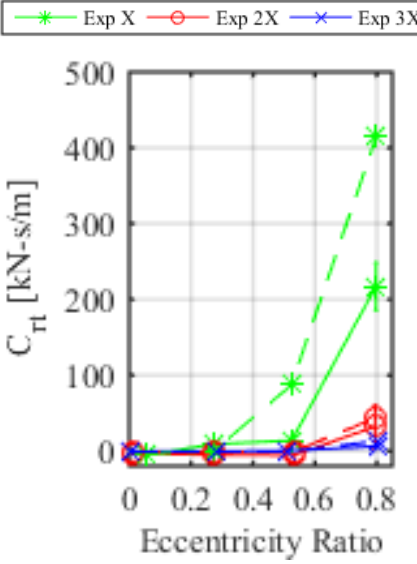

(a)

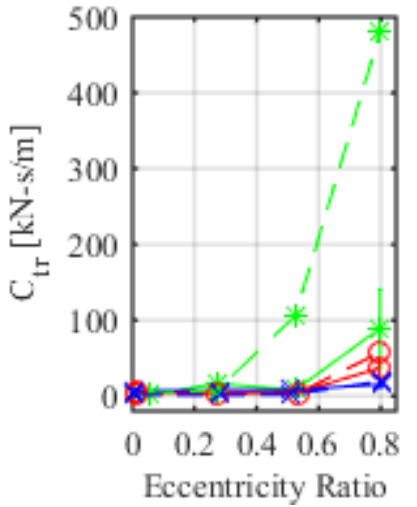

(b)
Figure 23. $\Delta P=6.21 \mathrm{bar}$ and $\omega=4 \mathrm{krpm}$ (a) Measured and predicted $C_{t r}$ versus $\varepsilon_{0}$. (b) Measured and predicted $C_{r t}$ versus $\varepsilon_{0}$.

\section{Virtual Mass}

Figure 25 shows $M_{t t}$ and $M_{r r}$ versus $\varepsilon_{0}$ for all clearances at $\Delta P=2.07$ bar and $\omega=4 \mathrm{krpm}$. Measured $M_{t t}$ and $M_{r r}$ decrease as $\varepsilon_{0}$ increases for the $1 \mathrm{X}$ clearance seal. They are largely independent of $\varepsilon_{0}$ for $2 \mathrm{X}$ and $3 \mathrm{X}$ clearance seals. For the $1 \mathrm{X}$ clearance seal, $M_{r r}$ becomes negative with a large amplitude for $\varepsilon_{0}=0.80$. Note that a negative direct virtual mass term can increase the natural frequency of the rotordynamic system. For example, for the $1 \mathrm{X}$ clearance seal at $\varepsilon_{0}=0.8, \Delta P=$ 2.07 bar and $\omega=4 \mathrm{krpm}$, comparing $M_{r r} \omega^{2}$ to $K_{r r}$, the resultant effecctive $K_{r r}$ increases by about $9 \%$.

For the $1 \mathrm{X}$ seal, predicted $M_{r r}$ is about 3 times lower than predicted $M_{r r}$ for the $2 \mathrm{X}$ and $3 \mathrm{X}$ clearance seals and independent of $\varepsilon_{0}$. The model predicts a negative $M_{r r}$ at $\varepsilon_{0}=$ 0.8 , and the data agrees. For the $2 \mathrm{X}$ and $3 \mathrm{X}$ clearance seals, predicted $M_{t t}$ is about 3 times lower than measured. The model predicts a negative $M_{t t}$ at $\varepsilon_{0}=0.53,0.8$ while the data shows $M_{t t}$ to be positive at all eccentricity ratios.

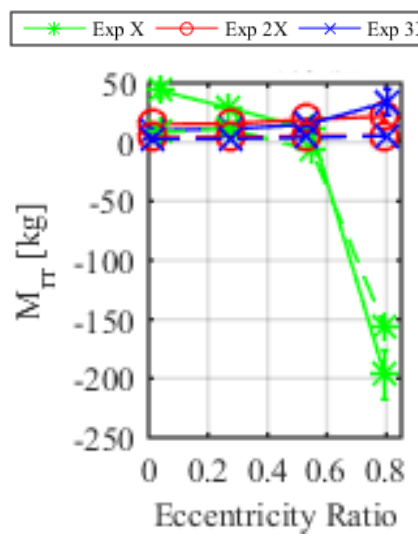

(a)

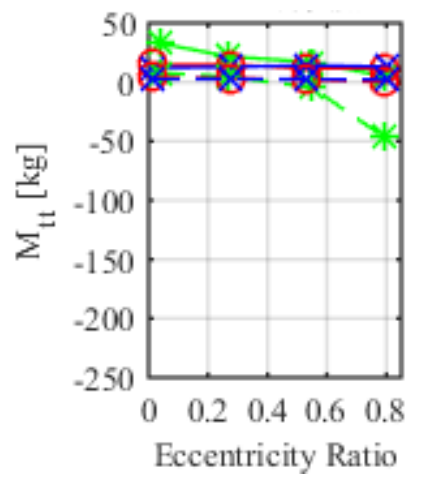

(b)
Figure 24. $\Delta P=2.07 \mathrm{bar}$ and $\omega=4 \mathrm{krpm}$ (a) Measured and predicted $M_{r r}$ versus. (b) Measured and predicted $M_{t t}$ versus $\varepsilon_{0}$.

Figure 26 shows measured $M_{t r}$ and $M_{r t}$ versus $\varepsilon_{0}$ for all clearances at $\Delta P=6.21$ bar and $\omega=6 \mathrm{krpm}$. For $\varepsilon_{0} \leq 0.53$, the error bars are the same order of magnitude and comparable to measured data at all the conditions tested. Therefore, these findings are questionable.

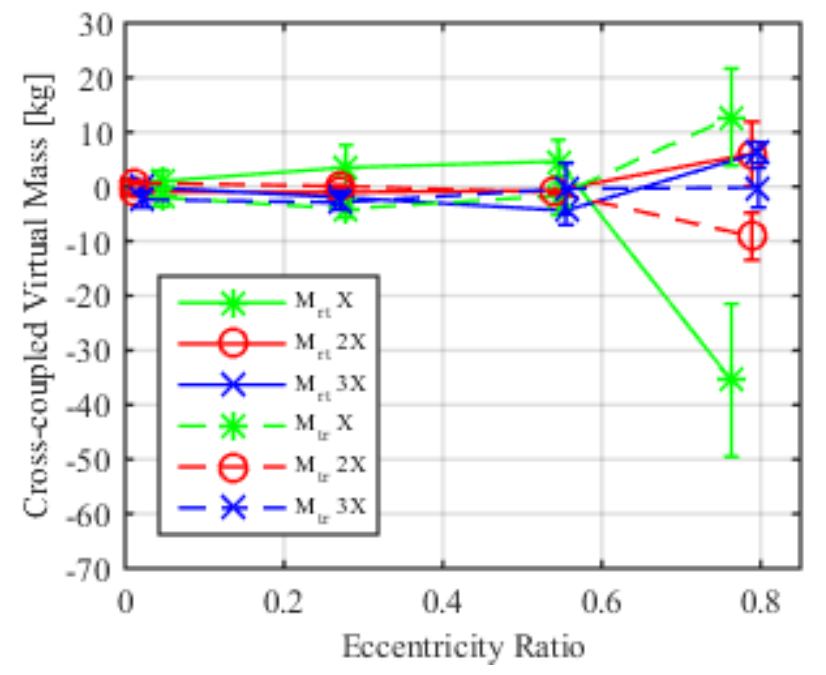

Figure 25. Measured $M_{t r}$ and $M_{r t}$ versus $\varepsilon_{0}$ at $\Delta \mathrm{P}=6.21 \mathrm{bar}$ and $\omega=6 \mathrm{krpm}$.

Table 1 shows the stability impact of $M_{t r}$ and $M_{r t}$ versus $\varepsilon_{0}$ for all clearances at $\Delta P=6.21 \mathrm{bar}$ and $\omega=6 \mathrm{krpm}$. Note that (a) if $M_{t r}$ and $M_{r t}$ have the same signs, they do not impact the stability of the system (referred as 0), (b) if $M_{t r}>0$ and $M_{r t}<$ 0 , they drive backward whirl (referred as Stabilizing FWD) and (c) if $M_{t r}<0$ and $M_{r t}>0$, they drive forward whirl (referred as Destabilizing FWD). 
Table 1. Stability impact of $M_{t r}, M_{r t}$ at $\Delta P=6.21$ bar and $\omega=6 \mathrm{krpm}$.

\begin{tabular}{|c|c|c|c|c|}
\cline { 2 - 5 } \multicolumn{1}{c|}{} & \multicolumn{4}{c|}{$\boldsymbol{\varepsilon}_{\mathbf{0}}$} \\
\hline Clearance & $\mathbf{0 . 0 0}$ & $\mathbf{0 . 2 7}$ & $\mathbf{0 . 5 3}$ & $\mathbf{0 . 8 0}$ \\
\hline $\mathbf{1 X}$ & $\begin{array}{c}\text { Destabilizing } \\
\text { FWD }\end{array}$ & $\begin{array}{c}\text { Destabilizing } \\
\text { FWD }\end{array}$ & $\begin{array}{c}\text { Destabilizing } \\
\text { FWD }\end{array}$ & $\begin{array}{c}\text { Stabilizing } \\
\text { FWD }\end{array}$ \\
\hline $\mathbf{2 X}$ & $\begin{array}{c}\text { Stabilizing } \\
\text { FWD }\end{array}$ & $\begin{array}{c}\text { Stabilizing } \\
\text { FWD }\end{array}$ & 0 & $\begin{array}{c}\text { Destabilizing } \\
\text { FWD }\end{array}$ \\
\hline $\mathbf{3 X}$ & 0 & 0 & 0 & $\begin{array}{c}\text { Destabilizing } \\
\text { FWD }\end{array}$ \\
\hline
\end{tabular}

\section{Whirl Frequency Ratio}

Figure 27 shows WFR [17] as function of $\varepsilon_{0}$ at $\Delta P=$ $4.14 \mathrm{bar}$ and $\omega=6 \mathrm{krpm}$. For the $1 \mathrm{X}$ and $2 \mathrm{X}$ clearance seals, WFR drops from approximately 0.5 to zero in moving from $\varepsilon_{0}$ $=0.53$ to $\varepsilon_{0}=0.8$. Note that this behavior resembles that of a plain journal bearing. For a clearance of $3 \mathrm{X}$, since $K_{t r}$ and $K_{r t}$ have the same sign, WFR remains zero at all eccentricity ratios.

The model predicts well for $1 \mathrm{X}$ and $2 \mathrm{X}$ clearance. However, for the $3 \mathrm{X}$ clearance seal, measured $K_{t r}$ and $K_{r t}$ have the same signs producing WFR $=0$. The model predicts different signs for $K_{t r}$ and $K_{r t}$ netting WFR $\cong 0.5$. Although not shown here, WFR is independent of $\Delta \mathrm{P}$ and $\omega$ for all the three clearances.

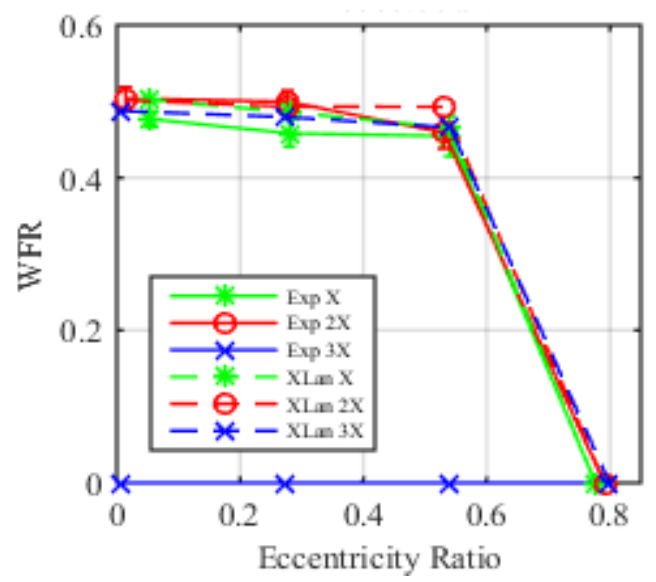

Figure 26. Measured and Predicted WFR versus $\varepsilon_{0}$ at $\Delta P=4.14$ bar and $\omega=6 \mathrm{krpm}$.

Note for the $3 \mathrm{X}$ clearance seal, $K_{r r}$ and $K_{t t}$ are negative for most of the test cases. The pump's first critical speed depends on the direct stiffness. Negative direct stiffness values would drop the natural frequency, thus worsening stability. For an ESP, a negative stiffness could cause the rotor to rub against the stator wall. However, unless there are different signs for $K_{t r}$ and $K_{r t}$, a seal will not cause a dynamic instability.

\section{CONCLUSION}

As expected, volumetric rate leakage $\dot{Q}$ increases as $C_{r}$ and $\Delta$ P increase. $\dot{Q}$ increases as $\varepsilon_{0}$ increases.

Upstream circumferential velocity $v_{i}$ is measured at one location with a pitot-tube (refer to Fig. 13 and 14 for location of inlet pitot-tube). As expected, $v_{i}$ increases as $C_{r}$ and $\omega$ increase.

Interestingly, $v_{i}$ is influenced by the inlet velocity from the pre-swirl insert $v_{\text {insert }}$ (refer Eq. (6)) to the extent that generally $v_{i}(3 \mathrm{X})>v_{i}(2 \mathrm{X})>v_{i}(1 \mathrm{X})$. As $\Delta P$ increases, $v_{i}$ tends to trend more with $v_{\text {insert }}$ and less with $R \omega$.

Notably for the $1 \mathrm{X}$ clearance seal at $\varepsilon_{0}=0.27, \phi \geq 90^{\circ}$, an indication that fluid inertia effects are important [12]. For the $3 \mathrm{X}$ clearance seal, $\phi \cong 180^{\circ}$ at $\varepsilon_{0}=0.27,0.53, \Delta \mathrm{P}=2.07 \mathrm{bar}$ and $\omega=8 \mathrm{krpm}$. This implies that there is no forward destabilizing force and that the centering force is negative.

As expected, for the $1 \mathrm{X}$ and $2 \mathrm{X}$ clearance seals, the applied static load $F_{s}$ increases as $\varepsilon_{0}$ increases, and decreases as $C_{r}$ increases. For the $1 \mathrm{X}$ and $2 \mathrm{X}$ clearance seals, measured applied static load is positive at all test conditions. For the $3 \mathrm{X}$ clearance seal, $F_{S}$ is negative at $\varepsilon_{0}=0.27,0.53, \Delta \mathrm{P}=2.07$ bar and $\omega=$ $8 \mathrm{krpm}$. This result agrees with the corresponding static loaddeflection- attitude angle results.

The following points summarize the most important results of the dynamic measurements:

- For the $1 \mathrm{X}$ and $2 \mathrm{X}$ clearance seals, SBs have no impact on the rotordynamic coefficients.

- For the 3X clearance seal, measured direct stiffness coefficients are negative. Therefore: (a) the natural frequencies of the pump would drop, and (b) For sufficiently large negative direct stiffness values the rotor could be sucked in to the stator.

- For the 3X clearance seal, swirl brakes were effective in making $K_{t r}$ and $K_{r t}$ both positive. Thus the seal's cross-coupled stiffness coefficients are no longer destabilizing. This result becomes less important, since direct stiffness coefficients are negative.

- Measured and predicted $C_{t r}$ and $C_{r t}$ are both positive for all clearances at most of the test conditions an indication that they will act as direct damping as opposed to gyroscopic damping.

- For the $1 \mathrm{X}$ clearance seal, measured virtual mass coefficients are negative at some test conditions, an indication that they could increase the natural frequency of the pump.

- Predictions generally agree well with measurements. Most important discrepancies pertain to stiffness coefficients for the $3 \mathrm{X}$ clearance seal. The model [1] fails to predict: (a) negative direct stiffness coefficients, and (b) same signs for the cross-coupled stiffness coefficients. 


\section{REFERENCES}

[1] Zirkelback, N., and San Andrés, L., (1996), "Bulk-Flow Model for the Transition to Turbulence Regime in Annular Seals," STLE Tribology Transactions, Vol 39 No 4, P. 835842.

[2] Lomakin, A., 1958, "Calculation of Critical Number of Revolutions and the Conditions Necessary for Dynamic Stability of Rotors in High-Pressure Hydraulic Machines When Taking Into Account Forces Originating in Sealings," Journal for Power and Mechanical Engineering (In Russian), 14.

[3] Pinkus, O., and Sternlicht, B., 1961, Theory of Hydrodynamic Lubrication, New York: McGraw-Hill.

[4] Childs, D., Norrbin, C., and Phillips, S., 2014 "A latera rotordynamics primer on electrical submersible pump: (ESP's) for deep subsea applications," in Proceedings of the 30th Pump User's Symposia, .

[5] Childs, D.W., 2013, Turbomachinery Rotordynamics with Case Studies, Wellborn, Texas: Minter Spring Publishing.

[6] Black H.F., Allaire, P., and Barret, L., 1981, "Inlet Flow Swirl in Short Turbulent Annular Seal Dynamics," in Ninth International Conference on Fluid Sealing, Noordwijkerhout, Netherlands, pp. 141-152.

[7] Benckert, H., and Wachter, J., 1980 "Flow Induced Spring Constants of Labyrinth Seals for Applications in Rotor Dynamics," in Proceedings of the 1st Workshop on Rotordynamic Instability Problems in High-Performance Turbomachinery, College Station, Texas, Texas A\&M University, pp 189-212.

[8] Massey, I., (1985), "Subsynchronous Vibration Problems in High-Speed Multistage Centrifugal Pumps," Proceedings, 14th Turbomachinery Symposium, organized by Texas A\&M University, pp. 11-16.

[9] Najeeb, O.A., and Childs, D.W., 2017, Static and Rotordynamic Analysis of a Plain Annular (Liquid) Seal in The Laminar Regime With a Swirl Brake for Three Clearances, Texas A\&M University, College Station, Texas.

[10] Kaul, A., 1999, "Design and Development of a Test Setup for the Experimental Determination of the Rotordynamic and Leakage Characteristics of Annular Bushing Oil Seals", College Station, Texas: Texas A\&M University.

[11] Moreland, A. J., 2016, "Moreland - Effect of Eccentricity and Pre-swirl on Smooth Stator_Grooved Rotor Liquid Annular Seals, Measured Static and Dynamic Results," M.S. Thesis, Texas A\&M University, College Station.

[12] You HI, Lu SS. The Effect of Fluid Inertia on the Operating Characteristics of a Journal Bearing. ASME. $J$. Tribol. 1988;110 (3):499-502.

[13] Rouvas, C., and Childs, D.W., 1993, "A Parameter Identification Method for the Rotordynamic Coefficients of a High Reynolds Number Hydrostatic Bearing," Jounal of Vibration and Acoustics, 115, pp. 264-270.

[14] Childs, D.W., and Hale, K., 1994, "A Test Apparatus and Facility to Identify the Rotordynamic Coefficients of High-Speed Hydrostatic Bearings," Journal of Tribology, 116, pp. 337-343.

[15] Beckwith, T., Marangoni, R., and Lienhard, V., 2007, Mechanical Measurements, Pearson Education, Inc, Upper Saddle River, NJ.

[16] Glienicke, J., 1966-67, "Experimental Investigation of the Stiffness and Damping Coefficients of Turbine Bearings and Their Application to Instability Prediction," in Proceedings of IMechE 1966-67, 181, pp. 116-129.

[17] San Andres, L., 1991, "Effect of Eccentricity on the Force Response of a Hybrid Bearing," Tribology Transactions, 34, pp. 537-544. 